\title{
Nephritogenic mAb 5-1-6 is directed at the extracellular domain of rat nephrin
}

Peter S. Topham, Hiroshi Kawachi, Samir A. Haydar, Sumant Chugh,

Theresa A. Addona, Kathryn B. Charron, Lawrence B. Holzman, Michael Shia,

Fujio Shimizu, and David J. Salant

J. Clin. Invest. 104:1559-1566 (1999).

\section{Acknowledgments}

This work was supported by research grants DK-48236 (to D.J. Salant) and DK-47566 (to L.B. Holzman) from the National Institutes of Diabetes and Digestive and Kidney Diseases. S. Chugh is the recipient of a National Kidney Foundation research fellowship. Grant-Aids for Science Research (C) (11671031 to H. Kawachi) from the Ministry of Education, Science, Culture and Sports, Japan.

In the final stages of the production process, the last sentence in the Acknowledgments section was accidentally left out; the corrected paragraph appears above. We regret the error. 